\title{
Association of the receptor for advanced glycation end- products (RAGE) gene polymorphisms in Malaysian patients with chronic kidney disease
}

Foo Nian Wong, Kek Heng Chua, Umah Rani Kuppusamy, Chew Ming Wong, Soo Kun Lim, Jin Ai Mary Anne Tan

Background. Chronic kidney disease (CKD) is a condition associated with progressive loss of kidney function and kidney damage. The two common causes of CKD are diabetes mellitus and hypertension. Other causes of CKD also include polycystic kidney disease, obstructive uropathy and primary glomerulonephritis. The receptor for advanced glycation end-products (RAGE) is a multi-ligand cell surface receptor of the immunoglobulin superfamily and it has been associated with kidney disease in both non-diabetic and diabetic patients. Presently, data on the association between RAGE polymorphisms and CKD in the Malaysian population is limited, while numerous studies have reported associations of RAGE polymorphisms with diabetic complications in other populations. The present study aims to explore the possibility of using RAGE polymorphisms as candidate markers of CKD in Malaysian population by using association analysis.

Methods. A total of 102 non-diabetic CKD patients, 204 diabetic CKD patients and 345 healthy controls were enrolled in the study. DNA isolated from blood samples were subjected to genotyping of RAGE G82S, -374T/A, -429T/C, 1704G/T and 2184A/G polymorphisms using real-time polymerase chain reaction (PCR). The 63-bp deletion, a polymorphism in the RAGE gene promoter, was genotyped using conventional PCR method and visualized using agarose gel electrophoresis. The collective frequencies of genotypes with at least one copy of the minor alleles of the four polymorphisms were compared between the non-diabetic CKD patients, diabetic CKD patients and healthy controls. Results. After adjustment of age, gender and ethnic groups in binary logistic regression analysis, the G82S CT + TT genotypes were associated with non-diabetic CKD patients when compared with diabetic CKD patients $(p=0.015, \mathrm{OR}=1.896,95 \% \mathrm{Cl}=1.132$ to 3.176). After further adjustment of CKD comorbidities, the G82S CT + TT genotypes were still associated with non-diabetic CKD patients when compared with diabetic CKD patients $(p=0.011, \mathrm{OR}=2.024,95 \% \mathrm{Cl}=1.178$ to 3.476). However, it cannot be suggested that G82S polymorphism was associated with CKD in non-diabetic patients in this study. This is because there were no significant differences in the frequencies of G82S CT $+\pi$ genotypes between non-diabetic CKD patients and healthy controls. In addition, the RAGE 
-374T/A, -429T/C, 1704G/T, 2184A/G and 63-bp deletion polymorphisms were also not associated with non-diabetic CKD patients and diabetic CKD patients in this study. Conclusion. The G82S, -374T/A, -429T/C, 1704G/T, 2184A/G and 63-bp deletion polymorphisms examined in this study were not associated with chronic kidney disease in the Malaysian patients. 
1 Association of the receptor for advanced glycation end-products (RAGE) gene 2 polymorphisms in Malaysian patients with chronic kidney disease

4 Foo Nian Wong ${ }^{1}$, Kek Heng Chua ${ }^{1}$, Umah Rani Kuppusamy ${ }^{1}$, Chew Ming Wong ${ }^{2}$, Soo Kun Lim ${ }^{2}$ 5 and Jin Ai Mary Anne Tan ${ }^{1}$.

$6{ }^{1}$ Department of Biomedical Science, Faculty of Medicine, University of Malaya, Kuala Lumpur, 7 Malaysia

$8 \quad{ }^{2}$ Department of Medicine, Faculty of Medicine, University of Malaya, Kuala Lumpur, Malaysia 9

10 Corresponding Author:

11 Jin Ai Mary Anne Tan ${ }^{1}$

12 Department of Biomedical Science, Faculty of Medicine, University of Malaya, 50603 Kuala Lumpur, Malaysia.

14 E-mail address: maryanne@um.edu.my 


\section{Abstract}

21

22

Background. Chronic kidney disease (CKD) is a condition associated with progressive loss of kidney function and kidney damage. The two common causes of CKD are diabetes mellitus and hypertension. Other causes of CKD also include polycystic kidney disease, obstructive uropathy and primary glomerulonephritis. The receptor for advanced glycation end-products (RAGE) is a multi-ligand cell surface receptor of the immunoglobulin superfamily and it has been associated with kidney disease in both non-diabetic and diabetic patients. Presently, data on the association between RAGE polymorphisms and CKD in the Malaysian population is limited, while numerous studies have reported associations of RAGE polymorphisms with diabetic complications in other populations. The present study aims to explore the possibility of using RAGE polymorphisms as candidate markers of CKD in Malaysian population by using association analysis.

Methods. A total of 102 non-diabetic CKD patients, 204 diabetic CKD patients and 345 healthy controls were enrolled in the study. DNA isolated from blood samples were subjected to genotyping of RAGE G82S, -374T/A, -429T/C, 1704G/T and 2184A/G polymorphisms using realtime polymerase chain reaction (PCR). The 63-bp deletion, a polymorphism in the RAGE gene promoter, was genotyped using conventional PCR method and visualized using agarose gel electrophoresis. The collective frequencies of genotypes with at least one copy of the minor alleles of the four polymorphisms were compared between the non-diabetic CKD patients, diabetic CKD patients and healthy controls.

Results. After adjustment of age, gender and ethnic groups in binary logistic regression analysis, the G82S CT + TT genotypes were associated with non-diabetic CKD patients when compared with diabetic CKD patients $(p=0.015, \mathrm{OR}=1.896,95 \% \mathrm{CI}=1.132$ to 3.176). After further adjustment of CKD comorbidities, the G82S CT + TT genotypes were still associated with non- 
43 diabetic CKD patients when compared with diabetic CKD patients $(p=0.011, \mathrm{OR}=2.024,95 \%$

$44 \mathrm{CI}=1.178$ to 3.476 ). However, it cannot be suggested that G82S polymorphism was associated

45 with CKD in non-diabetic patients in this study. This is because there were no significant

46 differences in the frequencies of G82S CT + TT genotypes between non-diabetic CKD patients

47 and healthy controls. In addition, the RAGE -374T/A, -429T/C, 1704G/T, 2184A/G and 63-bp

48 deletion polymorphisms were also not associated with non-diabetic CKD patients and diabetic

49 CKD patients in this study.

50 Conclusion. The G82S, -374T/A, -429T/C, 1704G/T, 2184A/G and 63-bp deletion

51 polymorphisms examined in this study were not associated with chronic kidney disease in the

52 Malaysian patients.

53

54

55

56

57

58

59

60

61

62 
Chronic kidney disease (CKD) is a general term for heterogeneous renal disorders which is characterized by progressive kidney damage and estimated glomerular filtration rate (eGFR) of less than $60 \mathrm{ml} / \mathrm{min} / 1.73 \mathrm{~m}^{2}$ for three months or more (Levey et al., 2003; Stevens \& Levey, 2009). CKD is an increasing health problem in Malaysia. In 2013, the prevalence of kidney failure patients requiring hemodialysis and peritoneal dialysis was 970 per million population (pmp) and 95 pmp respectively. In Malaysia, the prevalence of kidney failure has doubled over the last decade (National Renal Registry, 2014). The two common causes of kidney failure in Malaysia are diabetes mellitus and hypertension, with other causes being polycystic kidney disease, obstructive uropathy and chronic glomerulonephritis (National Renal Registry, 2014).

Receptor for advanced glycation end-products (RAGE) is a multi-ligand cell surface receptor of the immunoglobulin superfamily. The receptors bind to advanced glycation end-products (AGEs), certain members of S100/calgranulin, amphoterin, amyloid $\beta$-sheet fibrils, and advanced oxidation protein products (Kalea, Schmidt \& Hudson, 2009; Ramasamy, Yan \& Schmidt, 2009). The interaction between RAGE and its ligand triggers signal transduction which results in various cellular effects such as inflammation, oxidative stress, altered gene expression and apoptosis (Kalea, Schmidt \& Hudson, 2009; Xie et al., 2013). Furthermore, RAGE has also been studied in association with pathogenesis of kidney diseases in animal models (Myint et al., 2006; Guo et al.,

82 2008; Reiniger et al., 2010).

83 The human RAGE gene is located in the major histocompatibility complex (MHC) class III region on chromosome 6p21.3 (Kalea, Schmidt \& Hudson, 2009). Numerous polymorphisms have been 
85 identified in the promoter region, exons and introns of the RAGE gene (Hudson, Stickland \&

86 Grant, 1998; Hudson et al., 2001; Kanková et al., 2001). Many studies have reported on the

87 associations of the common RAGE polymorphisms such as G82S, -374T/A, -429T/C, 1704G/T,

$882184 \mathrm{~A} / \mathrm{G}$ and 2250G/A with the development of diabetic nephropathy (Matsunaga-Irie et al., 2004;

89 Prevost et al., 2005; Kanková et al., 2005; Lindholm et al., 2006). Moreover, several RAGE

90 polymorphisms have also been investigated in association with lupus nephritis (Martens et al., 91 2012).

92 Given the associations of several RAGE polymorphisms with kidney diseases in the published

93 literature, the present study aims to explore the possibility of using RAGE polymorphisms as

94 candidate markers of CKD in Malaysian population by using association analysis. This study

95 investigates the G82S, -374T/A, -429T/C, 1704G/T, 2184A/G and 63-bp deletion polymorphisms

96 based on their effects on RAGE expression and function which potentially affect CKD

97 pathogenesis: (i) G82S polymorphism is a missense mutation in exon 3 of the RAGE gene which

98 potentially regulates RAGE function (Kalea, Schmidt \& Hudson, 2009), (ii) the polymorphisms in

99 the transcriptional start site of RAGE such as -374T/A, -429T/C and 63-bp deletion

100 polymorphisms regulate the transcription of RAGE (Hudson et al., 2001), and (iii) the 1704G/T

101 polymorphism and 2184A/G polymorphism may be responsible for alternative splicing that

102 produces endogenous secretory RAGE which is cytoprotective against RAGE ligands (Yonekura

103 et al., 2003; Schlueter et al., 2003).

104

105 Materials \& Methods

106

Subject recruitment 
107 CKD patients (40 - 75-year-old) whose eGFR were less than $60 \mathrm{ml} / \mathrm{min} / 1.73 \mathrm{~m}^{2}$ were recruited 108 from University Malaya Medical Centre (UMMC), Kuala Lumpur between September 2013 and

109 November 2014. To further confirm their CKD status, the eGFR of the patients for the past six 110 months were checked to be constantly less than $60 \mathrm{ml} / \mathrm{min} / 1.73 \mathrm{~m}^{2}$. Estimated GFR was determined 111 using the Modified 4-variable Modification of Diet in Renal Disease (MDRD) study equation 112 (Levey et al., 2006). The eGFR was measured on the day of recruitment and the average eGFR of 113 each patient group was calculated. Patients with acute kidney injury which is reversible and kidney 114 transplant recipients whose renal function has reverted to satisfying levels were excluded, as this 115 study aims to investigate kidney diseases which are progressive in nature. Diabetic CKD patients 116 were those with type 2 diabetes $(n=204)$ and non-diabetic CKD patients comprised of patients with 117 hypertension (54), chronic glomerulonephritis (26), obstructive uropathy (9), analgesic 118 nephropathy (7), polycystic kidney disease (4), urate nephropathy (1) and renal tubular acidosis 119 (1). Healthy controls (35 - 65-year-old, $n=345)$ were recruited from blood donors without diabetes, 120 hypertension, heart disease and kidney disease. Peripheral venous blood (3-6 ml) was collected in 121 EDTA tubes for DNA analysis.

122 This study was approved by the Medical Ethics Committee UMMC (reference number: 982.17) in 123 accordance with the Declaration of Helsinki. Verbal and written informed consent were also 124 obtained from all patients and healthy controls before blood collection.

DNA extraction and genotyping using commercial polymorphism genotyping assays

Blood specimens were kept at $-20^{\circ} \mathrm{C}$ until DNA extraction. DNA was extracted using an in-house

127 modified salting out procedure (Miller, Dykes \& Polesky, 1988). Genotyping for the RAGE G82S, $128-374 \mathrm{~T} / \mathrm{A},-429 \mathrm{~T} / \mathrm{C}, 1704 \mathrm{G} / \mathrm{T}$ and $2184 \mathrm{~A} / \mathrm{G}$ polymorphisms were performed using the TaqMan ${ }^{\circledR}$ 129 Single Nucleotide Polymorphism (SNP) Genotyping Assays (Life Technologies, USA) (Table 1) 
130 according to the manufacturer's instructions. Briefly, $1 \mu l$ of diluted DNA sample, $5 \mu 1$ of $2 \mathrm{X}$

131 TaqMan ${ }^{\circledR}$ GTXpress ${ }^{\mathrm{TM}}$ Master Mix (Life Technologies, USA), $0.5 \mu 1$ of 20X TaqMan ${ }^{\circledR}$ SNP

132 Genotyping Assays and 3.5 $\mu 1$ DNase-free double-distilled water were mixed to obtain a $10 \mu 1$

133 SNP genotyping reaction for each DNA sample.

134 Genotypes were determined by real-time polymerase chain reaction (PCR) using Applied

135 Biosystems Fast 7500 Real-Time Thermal Cycler. The pre-PCR stage was $60^{\circ} \mathrm{C}$ for 1 minute prior

136 to the holding stage at $95^{\circ} \mathrm{C}$ for 20 seconds. PCR conditions include 40 cycles of denaturation at

$13795^{\circ} \mathrm{C}$ for 3 seconds followed by annealing and elongation at $60^{\circ} \mathrm{C}$ for 30 seconds with a final post-

138 PCR stage at $60^{\circ} \mathrm{C}$ for 1 minute. Results were analyzed using the Applied Biosystems ${ }^{\circledR} 7500$ Fast

139 Real-Time PCR System and Applied Biosystems ${ }^{\circledR}$ TaqMan ${ }^{\circledR}$ Genotyper Software.

140 Screening RAGE 63-bp deletion using conventional PCR method

141 The RAGE 63-bp deletion polymorphism was detected using conventional PCR method. Briefly,

$14210 \mu \mathrm{l}$ of final PCR reaction mixture contained 1X DreamTaq Buffer (Thermo Scientific), $0.45 \mathrm{U}$

143 DreamTaq DNA Polymerase (Thermo Scientific), $0.09 \mathrm{mM}$ deoxyribonucleotide triphosphate

144 (dNTP) (Thermo Scientific), $0.22 \mu \mathrm{M}$ forward primer, $0.22 \mu \mathrm{M}$ reverse primer and $80 \mathrm{ng}$ sample

145 DNA. The sequences of forward primer and reverse primer are

146 5'- GGGGCAGTTCTCTCCTCACT-3' and 5'-CATGCCTTTGGGACAAGAGT-3' respectively.

147 The PCR was performed with an initial incubation at $94^{\circ} \mathrm{C}$ for $5 \mathrm{~min}$, followed by 40 cycles

148 consisting of $94^{\circ} \mathrm{C}$ for $30 \mathrm{~s}, 63.3^{\circ} \mathrm{C}$ for $40 \mathrm{~s}$ and $72^{\circ} \mathrm{C}$ for $40 \mathrm{~s}$. One cycle of final extension at $72^{\circ} \mathrm{C}$

149 for 5 min was programmed to complete the amplification. The PCR products were visualized using 150 electrophoresis on $1.5 \%$ agarose gels.

151 Statistical analyses 
152 Hardy-Weinberg equilibrium calculator including analysis for ascertainment bias, a web-tool

153 (http://www.oege.org/software/hwe-mr-calc.shtml), was used to assess Hardy-Weinberg

154 equilibrium (HWE) for each RAGE polymorphism using Chi-squared test to examine the

155 differences in genotype distribution between observed and expected frequencies (Rodriguez,

156 Gaunt \& Day, 2009). The significance of HWE deviation was set at $p<0.05$.

157 The statistical power of this unmatched case-control study was estimated using Quanto, version

1581.2 (Gauderman \& Morrison, 2001). In this analysis, the statistical power was calculated for

159 comparing the frequency of genotype with at least one copy of the minor allele of each RAGE

160 polymorphism between a pair of subject groups. The gene only hypothesis and dominance

161 inheritance mode were selected for power calculation.

162 Chi-squared test was used to detect the significant difference in each categorical variable. The 163 statistical significance of differences in mean values was analyzed using independent $t$ test or one164 way analysis of variance (ANOVA). Binary logistic regression analysis was used to estimate the 165 probability of CKD development attributed to RAGE polymorphism genotypes by adjusting the 166 covariates such as age, gender, ethnic groups and comorbidities of CKD. Odds ratio and 95\% 167 confidence interval were calculated. These statistical analyses were performed using the Statistical 168 Package for Social Sciences, version 20 (SPSS Inc., Chicago, IL). The significance level was set 169 at $p<0.05$.

\section{Results}

172 The demographic data, eGFR and comorbidities of the study subjects are shown in Table 2. Both

173 non-diabetic CKD $\left(P_{b}<0.001\right)($ Table 2$)$ and diabetic CKD patients $\left(P_{c}<0.001\right)($ Table 2$)$ were 
174 older compared to the healthy controls while there were no significant differences in categorical

175 variables such as gender and ethnic groups between the study subject groups $(P>0.05)($ Table 2$)$.

176 Comparison between non-diabetic CKD and diabetic CKD patients showed significant difference

177 in the eGFR levels $\left(P_{a}=0.001\right)$ (Table 2$)$. The CKD patients were also affected with comorbidities

178 such as hypertension, dyslipidemia, ischemic heart disease and stroke. Chi-squared analyses

179 showed that there were significantly more diabetic CKD patients with hypertension $\left(P_{a}=0.043\right)$

180 (Table 2) and ischemic heart disease $\left(P_{a}=0.002\right)$ (Table 2) than non-diabetic CKD patients.

181 The collective frequencies of genotypes with at least one copy of the minor alleles of G82S, -

$182374 \mathrm{~T} / \mathrm{A},-429 \mathrm{~T} / \mathrm{C}, 1704 \mathrm{G} / \mathrm{T}, 2184 \mathrm{~A} / \mathrm{G}$ and 63-bp deletion polymorphisms in the Malaysian CKD

183 patients and healthy controls are shown in Table 3. Genotype distributions of the six

184 polymorphisms in the non-diabetic CKD, diabetic CKD and healthy controls were in HWE except

185 for the non-diabetic CKD patients with -429T/C polymorphism, diabetic CKD patients with G82S

186 and $1704 \mathrm{G} / \mathrm{T}$ polymorphisms as well as health controls with $2184 \mathrm{~A} / \mathrm{G}$ polymorphism

187 (Supplementary information, Table S1).

188 The frequencies of the genotypes with at least one copy of the G82S T allele (CT + TT genotypes)

189 were significantly higher in the non-diabetic CKD patients than in the diabetic CKD patients

190 (Table 3). Overall, 38.2\% of the non-diabetic CKD patients carried at least one copy of the G82S

191 T allele. After adjustment of age, gender and ethnic groups, binary logistic regression analysis

192 indicated that the G82S CT + TT genotypes were associated with non-diabetic CKD patients as 193 compared with diabetic CKD patients $(P=0.015, \mathrm{OR}=1.896,95 \% \mathrm{CI}=1.132$ to 3.176) (Table

194 3, Model 1). Further adjustment of CKD comorbidities showed that the G82S CT + TT genotypes

195 were still associated with non-diabetic CKD patients as compared with diabetic CKD patients $(P$ $196=0.011, \mathrm{OR}=2.024,95 \% \mathrm{CI}=1.178$ to 3.476) $($ Table 3, Model 2). However, the G82S CT $+\mathrm{TT}$ 
197 genotypes were not associated with non-diabetic CKD patients and diabetic CKD patients as 198 compared with healthy controls $(P>0.05)$ (Table 3$)$.

199 The genotypes consisting the minor alleles of RAGE -374T/A, -429T/C, 1704G/T, 2184A/G and 200 63-bp deletion polymorphisms were also not associated with non-diabetic CKD patients and 201 diabetic CKD patients $(P>0.05)$ (Table 3). Figure 1 shows the representative gel image of 202 electrophoresed PCR products with or without 63-bp deletion. In this study, the study subjects with 63-bp deletion are heterozygous for the polymorphism and none of the study subjects are homozygous for this particular deletion.

Discussion

207

208

209

210

211

212

213

214

215

216

217 218

Published studies have corroborated the role of RAGE in the development of diabetes-associated renal diseases, for example, inhibition of RAGE through pharmacological antagonism or gene deletion showed significant improvements in the pathological features of diabetic nephropathy in animal models (Wendt et al., 2003; Reiniger et al., 2010). In addition to diabetic nephropathy, RAGE is also associated with the pathogenesis of non-diabetic renal diseases, for example, podocyte stress and glomerulosclerosis were elicited in doxorubicin-treated mice, but these features were decreased in the homozygous RAGE-null mice treated with doxorubicin (Guo et al., 2008). In view of the potential pathological role of RAGE in kidney diseases, the associations of RAGE gene polymorphisms with CKD were investigated in this study as the polymorphisms may be fundamentally important in CKD development.

In addition to renal diseases, previous human population studies have shown that RAGE polymorphisms were associated with cardiovascular diseases such as ischemic heart disease and 
219 stroke (Zee et al., 2006; Poon et al., 2010). In order to investigate accurately the association of

220 RAGE polymorphisms with CKD, the comorbidities such as ischemic heart disease, stroke and

221 their risk factors (hypertension and dyslipidemia) were adjusted in binary logistic regression

222 analysis to eliminate their confounding effects.

223 In the present study, the G82S CT + TT genotypes were associated with non-diabetic CKD patients

224 when compared with diabetic CKD patients, but not with healthy controls. Thus, it cannot be

225 suggested that the $\mathrm{T}$ allele is associated with CKD in non-diabetic patients in this study. Studies

226 on the association between G82S polymorphism and kidney disease have showed conflicting

227 results. The frequency of genotype with at least one copy of G82S T allele was significantly higher

228 in type 1 diabetic patients with advanced nephropathy compared with diabetic patients with less

229 severe nephropathy or no nephropathy in France and Belgium (Prevost et al., 2005). On the

230 contrary, this polymorphism was not associated with type 1 diabetic nephropathy and lupus

231 nephritis in Denmark and the Netherlands respectively (Poirier et al., 2001; Martens et al., 2012).

232 The -374T/A, -429T/C, 1704G/T, 2184A/G and 63-bp deletion polymorphisms did not show any

233 association with non-diabetic CKD and diabetic CKD patients in this study. However, published

234 literature have reported contradictory results for these polymorphisms. The -374T/A

235 polymorphism was associated with diabetic complications including diabetic nephropathy in a

236 Swedish population (Lindholm et al., 2006) and has also been implicated in more rapid decline of

237 renal function in Italian CKD patients (Baragetti et al., 2013). In contrast, this polymorphism was

238 protective against albumin excretion and cardiovascular disease in type 1 diabetic Finnish patients

239 (Pettersson-Fernholm et al., 2003).

240 Only limited reports are available on the associations of the RAGE -429T/C, 1704G/T, 2184A/G

241 and 63-bp deletion polymorphisms with kidney diseases. In a linkage disequilibrium analysis, the 
242 frequency of a haplotype containing the $-429 \mathrm{~T} / \mathrm{C}$ and $2184 \mathrm{~A} / \mathrm{G}$ polymorphisms were significantly

243 higher in type 2 diabetic nephropathy (Kanková et al., 2005). Furthermore, the 1704 G/T

244 polymorphism showed a significant association with type 2 diabetic patients developing

245 nephropathy in a Japanese population (Matsunaga-Irie et al., 2004). The 2184A/G polymorphism

246 was associated with increased risk for diabetic nephropathy in type 2 diabetic patients from Central

247 Europe (Kaňková et al., 2007) but this polymorphism was reported to play a protective role against

248 diabetic nephropathy in Chinese type 2 diabetic patients (Cai et al., 2015). Another study showed

249 that the type 2 diabetic patients with the 63-bp deletion may be protected from diabetic 250 nephropathy, but the type 1 diabetic patients with 63-bp deletion were at risk of diabetic

251 nephropathy in a German population (Rudofsky et al., 2004). In addition to diabetic nephropathy,

252 the $-374 \mathrm{~T} / \mathrm{A},-429 \mathrm{~T} / \mathrm{C}$ and $2184 \mathrm{~A} / \mathrm{G}$ polymorphisms were also associated with lupus nephritis,

253 worsened proteinuria and decreased renal function in a Dutch population (Martens et al., 2012).

254 Although the RAGE polymorphisms investigated in this study were not associated with CKD, 255 published studies have demonstrated that some of these polymorphisms are associated with altered 256 expression and function of RAGE which may underlie disease development. Several lines of 257 evidence have suggested the importance of the G82S T allele in the mediation of RAGE-ligand 258 binding and activation of downstream signaling pathways. The G82S T allele renders higher 259 affinity of RAGE towards ligands such as AGEs and S100/calgranulin (Hofmann et al., 2002;

260 Osawa et al., 2007). Another study showed that the RAGE protein with G82S polymorphism 261 promoted $N$-linked glycosylation at the Asparagine 81 site, which was associated with increased 262 ligand binding and pro-inflammatory NF-кB activation (Park, Kleffmann \& Hessian, 2011). The 263 deleterious cellular effects resulting from increased ligand binding such as oxidative stress and 
264 inflammation (Kalea, Schmidt \& Hudson, 2009) are fundamental to CKD development (Ruiz et 265 al., 2013).

266 The RAGE -374T/A, -429 T/C and 63-bp deletion polymorphisms which occur in the 267 transcriptional start site of RAGE gene may affect the transcriptional regulation. A published study 268 showed that these polymorphisms resulted in an increase of transcriptional activity (Hudson et al., 269 2001), indicating an enhanced expression of RAGE which is associated with the progression and 270 severity of renal dysfunction (Wendt et al., 2003; Hou et al., 2004). However, the functional impact 271 of $1704 \mathrm{G} / \mathrm{T}$ and $2184 \mathrm{~A} / \mathrm{G}$ polymorphisms remain to be elucidated.

272 Despite the evidence of RAGE polymorphisms associating with kidney diseases, the selected

273 RAGE polymorphisms were not associated with CKD in the present study. A plausible explanation

274 for this discrepancy is the ethnic and regional differences between Malaysian and other 275 populations. Two published reports have provided an example of this concept that the association 276 of 2184A/G polymorphism with type 2 diabetic nephropathy in Central Europe (Kaňková et al., 277 2007) is contradictory to the decreased risk of type 2 diabetic nephropathy in the Chinese (Cai et 278 al., 2015). This highlights the possible influence of ethno-regional difference on the association 279 between polymorphism and disease. In addition, RAGE polymorphisms may not be CKD-specific 280 in Malaysian patients according to the findings in this study. Given the conflicting findings in the 281 association studies, the relationship between RAGE polymorphisms and kidney diseases should

282 be interpreted with caution.

283 The main limitation of this study was the subjects who were recruited only from a medical center 284 may not be a representative of the general population. Current sample size determined in a priori 285 power analysis could detect significant associations with $80 \%$ statistical power. During final 286 analysis, however, most of the comparisons were associated with low statistical power 
287 (Supplementary information, Table S2). The low statistical power could be attributed to the odds

288 ratio which is very close to the null value, small sample size and low frequency of risk allele

289 because statistical power is influenced by effect size, sample size and disease allele frequency

290 (Gordon, 2005; Schneider, 2013). The low statistical power in this study is likely due to the low

291 risk allele frequencies. For example, the risk allele frequencies of several RAGE gene

292 polymorphisms such as $-374 \mathrm{~T} / \mathrm{A},-429 \mathrm{~T} / \mathrm{C}$ and $2184 \mathrm{~A} / \mathrm{G}$ are lower in the Malaysian populations

293 compared with the Caucasian populations (Kanková et al., 2005; Kalousová et al., 2007).

294 Baragetti et al. (2013) demonstrated in a prospective study that the A allele of $-374 \mathrm{~T} / \mathrm{A}$ 295 polymorphism was associated with more rapid renal function decline. This suggests that RAGE 296 polymorphisms may affect CKD progression over a longer time span. Therefore, the relationships 297 between RAGE polymorphisms and CKD can be investigated using prospective study design to 298 validate the negative findings in the current study. Furthermore, the polymorphisms of other genes 299 such as transforming growth factor- $\beta 1$ (TGF- $\beta 1$ ), non-muscle myosin heavy chain 9 (MYH9) and apolipoprotein L1 (APOL1) have been shown in associations with kidney diseases (Freedman et al., 2009; Vuong et al., 2009; Langefeld et al., 2015). These candidate genes would serve as 302 promising tools for CKD marker discovery.

\section{Conclusion}

Based on the current findings, the RAGE G82S, -374T/A, -429T/C, 1704G/T, 2184A/G and 63bp deletion polymorphisms are not qualified to be the markers of CKD in Malaysian populations on the account of the null associations between these polymorphisms and CKD. Therefore, it may not be useful to predict CKD using RAGE polymorphisms in Malaysian patients. 


\section{References}

Baragetti I., Norata GD., Sarcina C., Baragetti A., Rastelli F., Buzzi L., Grigore L., Garlaschelli K., Pozzi C., Catapano AL. 2013. -374 T/A RAGE polymorphism is associated with chronic kidney disease progression in subjects affected by nephrocardiovascular disease. PloS one 8:e60089.

Cai W., Li J., Xu J., Liu Y., Zhang W., Xiao J., Zhu L., Liu J. 2015. Association of 2184AG Polymorphism in the RAGE Gene with Diabetic Nephropathy in Chinese Patients with Type 2 Diabetes. Journal of Diabetes Research 2015:1-6.

Freedman BI., Hicks PJ., Bostrom MA., Cunningham ME., Liu Y., Divers J., Kopp JB., Winkler CA., Nelson GW., Langefeld CD., Bowden DW. 2009. Polymorphisms in the non-muscle myosin heavy chain 9 gene (MYH9) are strongly associated with end-stage renal disease historically attributed to hypertension in African Americans. Kidney International 75:736745 .

Gauderman W., Morrison J. 2001. QUANTO documentation. (Technical report no. 157). Los Angeles, CA: Department of Preventive Medicine, University of Southern California.

Gordon D. 2005. Factors affecting statistical power in the detection of genetic association. Journal of Clinical Investigation 115:1408-1418.

Guo J., Ananthakrishnan R., Qu W., Lu Y., Reiniger N., Zeng S., Ma W., Rosario R., Yan SF., Ramasamy R., D’Agati V., Schmidt AM. 2008. RAGE mediates podocyte injury in adriamycin-induced glomerulosclerosis. Journal of the American Society of Nephrology: JASN 19:961-72.

Hofmann MA., Drury S., Hudson BI., Gleason MR., Qu W., Lu Y., Lalla E., Chitnis S., Monteiro J., Stickland MH., Bucciarelli LG., Moser B., Moxley G., Itescu S., Grant PJ., Gregersen PK., Stern DM., Schmidt AM. 2002. RAGE and arthritis: the G82S polymorphism amplifies the inflammatory response. Genes and immunity 3:123-35.

Hou FF., Ren H., Owen WF., Guo ZJ., Chen PY., Schmidt AM., Miyata T., Zhang X. 2004. Enhanced expression of receptor for advanced glycation end products in chronic kidney disease. Journal of the American Society of Nephrology : JASN 15:1889-96.

Hudson BI., Stickland MH., Futers TS., Grant PJ. 2001. Effects of novel polymorphisms in the RAGE gene on transcriptional regulation and their association with diabetic retinopathy. Diabetes 50:1505-11.

Hudson BI., Stickland MH., Grant PJ. 1998. Identification of polymorphisms in the receptor for advanced glycation end products (RAGE) gene: prevalence in type 2 diabetes and ethnic groups. Diabetes 47:1155-7.

Kalea AZ., Schmidt AM., Hudson BI. 2009. RAGE: a novel biological and genetic marker for 
vascular disease. Clinical science (London, England: 1979) 116:621-37.

347

348

349

350

351

352

353

354

355

356

357

358

359

360

361

362

363

364

365

366

367

368

369

370

371

372

373

374

375

376

377

378

379

380

381

382

383

384

385

386

Kalousová M., Jáchymová M., Mestek O., Hodková M., Kazderová M., Tesar V., Zima T. 2007. Receptor for advanced glycation end products--soluble form and gene polymorphisms in chronic haemodialysis patients. Nephrology, dialysis, transplantation : official publication of the European Dialysis and Transplant Association - European Renal Association 22:2020-6.

Kanková K., Márová I., Záhejský J., Muzík J., Stejskalová A., Znojil V., Vácha J. 2001. Polymorphisms 1704G/T and 2184A/G in the RAGE gene are associated with antioxidant status. Metabolism: clinical and experimental 50:1152-60.

Kanková K., Stejskalová A., Hertlová M., Znojil V. 2005. Haplotype analysis of the RAGE gene: identification of a haplotype marker for diabetic nephropathy in type 2 diabetes mellitus. Nephrology, dialysis, transplantation : official publication of the European Dialysis and Transplant Association - European Renal Association 20:1093-102.

Kaňková K., Stejskalová A., Pácal L., Tschoplová S., Hertlová M., Krusová D., IzakovičováHollá L., Beránek M., Vašků A., Barral S., Ott J. 2007. Genetic risk factors for diabetic nephropathy on chromosomes $6 \mathrm{p}$ and $7 \mathrm{q}$ identified by the set-association approach. Diabetologia 50:990-999.

Langefeld CD., Divers J., Pajewski NM., Hawfield AT., Reboussin DM., Bild DE., Kaysen GA., Kimmel PL., Raj DS., Ricardo AC., Wright JT., Sedor JR., Rocco M V., Freedman BI., Systolic Blood Pressure Intervention Trial (SPRINT). 2015. Apolipoprotein L1 gene variants associate with prevalent kidney but not prevalent cardiovascular disease in the Systolic Blood Pressure Intervention Trial. Kidney international 87:169-75.

Levey AS., Coresh J., Balk E., Kausz AT., Levin A., Steffes MW., Hogg RJ., Perrone RD., Lau J., Eknoyan G. 2003. National Kidney Foundation practice guidelines for chronic kidney disease: evaluation, classification, and stratification. Annals of internal medicine 139:13747.

Levey AS., Coresh J., Greene T., Stevens LA., Zhang YL., Hendriksen S., Kusek JW., Van Lente F. 2006. Using standardized serum creatinine values in the modification of diet in renal disease study equation for estimating glomerular filtration rate. Annals of internal medicine 145:247-54.

Lindholm E., Bakhtadze E., Sjögren M., Cilio CM., Agardh E., Groop L., Agardh C-D. 2006. The -374 T/A polymorphism in the gene encoding RAGE is associated with diabetic nephropathy and retinopathy in type 1 diabetic patients. Diabetologia 49:2745-55.

Martens HA., Nienhuis HLA., Gross S., van der Steege G., Brouwer E., Berden JHM., de Sévaux RGL., Derksen RHWM., Voskuyl AE., Berger SP., Navis GJ., Nolte IM., Kallenberg CGM., Bijl M. 2012. Receptor for advanced glycation end products (RAGE) polymorphisms are associated with systemic lupus erythematosus and disease severity in lupus nephritis. Lupus 21:959-68.

Matsunaga-Irie S., Maruyama T., Yamamoto Y., Motohashi Y., Hirose H., Shimada A., Murata M., Saruta T. 2004. Relation between development of nephropathy and the p22phox C242T and receptor for advanced glycation end product G1704T gene polymorphisms in type 2 
401

402

403

404

405

406

407

408

409

410

411

412

413

414

415

416

417

418

419

420

421

422

423

424

425

426

diabetic patients. Diabetes care 27:303-7.

Miller SA., Dykes DD., Polesky HF. 1988. A simple salting out procedure for extracting DNA from human nucleated cells. Nucleic acids research 16:1215.

Myint K., Yamamoto Y., Doi T., Kato I., Harashima A., Yonekura H., Watanabe T., Shinohara H., Takeuchi M., Tsuneyama K., Hashimoto N., Asano M., Takasawa S., Okamoto H., Yamamoto H. 2006. RAGE control of diabetic nephropathy in a mouse model: effects of RAGE gene disruption and administration of low-molecular weight heparin. Diabetes 55:2510-22.

National Renal Registry. 2014. 21th Report of the Malaysian Dialysis and Transplant Registry 2013. Kuala Lumpur.

Osawa M., Yamamoto Y., Munesue S., Murakami N., Sakurai S., Watanabe T., Yonekura H., Uchigata Y., Iwamoto Y., Yamamoto H. 2007. De-N-glycosylation or G82S mutation of RAGE sensitizes its interaction with advanced glycation endproducts. Biochimica et biophysica acta 1770:1468-74.

Park SJ., Kleffmann T., Hessian PA. 2011. The G82S polymorphism promotes glycosylation of the receptor for advanced glycation end products (RAGE) at asparagine 81: comparison of wild-type rage with the G82S polymorphic variant. The Journal of biological chemistry 286:21384-92.

Pettersson-Fernholm K., Forsblom C., Hudson BI., Perola M., Grant PJ., Groop P-H. 2003. The functional -374 T/A RAGE gene polymorphism is associated with proteinuria and cardiovascular disease in type 1 diabetic patients. Diabetes 52:891-4.

Poirier O., Nicaud V., Vionnet N., Raoux S., Tarnow L., Vlassara H., Parving HH., Cambien F. 2001. Polymorphism screening of four genes encoding advanced glycation end-product putative receptors. Association study with nephropathy in type 1 diabetic patients. Diabetes 50:1214-8.

Poon P., Szeto C., Chow K., Kwan B., Li P. 2010. Relation between polymorphisms of receptor for advanced glycation end products ( RAGE ) and cardiovascular diseases in Chinese patients with diabetic nephropathy . Clinical nephrology 73:44-50.

Prevost G., Fajardy I., Besmond C., Balkau B., Tichet J., Fontaine P., Danze PM., Marre M. 2005. Polymorphisms of the receptor of advanced glycation endproducts (RAGE) and the development of nephropathy in type 1 diabetic patients. Diabetes \& metabolism 31:35-39.

Ramasamy R., Yan SF., Schmidt AM. 2009. RAGE: therapeutic target and biomarker of the inflammatory response--the evidence mounts. Journal of leukocyte biology 86:505-12.

Reiniger N., Lau K., McCalla D., Eby B., Cheng B., Lu Y., Qu W., Quadri N., Ananthakrishnan R., Furmansky M., Rosario R., Song F., Rai V., Weinberg A., Friedman R., Ramasamy R., D’Agati V., Schmidt AM. 2010. Deletion of the Receptor for Advanced Glycation End Products Reduces Glomerulosclerosis and Preserves Renal Function in the Diabetic OVE26 Mouse. Diabetes 59:2043-2054.

Rodriguez S., Gaunt TR., Day INM. 2009. Hardy-Weinberg equilibrium testing of biological ascertainment for Mendelian randomization studies. American journal of epidemiology 
169:505-14.

Rudofsky G., Isermann B., Schilling T., Schiekofer S., Andrassy M., Schneider JG., Morcos M., Humpert PM., Sayed AAR., Witte S., Renn W., Pfohl M., Hamann A., Nosikov V., Schleicher E., Häring H-U., Ritz E., Nawroth PP., Bierhaus A. 2004. A 63bp deletion in the promoter of rage correlates with a decreased risk for nephropathy in patients with type 2 diabetes. Experimental and clinical endocrinology \& diabetes : official journal, German Society of Endocrinology [and] German Diabetes Association 112:135-41.

Ruiz S., Pergola PE., Zager RA., Vaziri ND. 2013. Targeting the transcription factor Nrf2 to ameliorate oxidative stress and inflammation in chronic kidney disease. Kidney international 83:1029-41.

Schlueter C., Hauke S., Flohr AM., Rogalla P., Bullerdiek J. 2003. Tissue-specific expression patterns of the RAGE receptor and its soluble forms--a result of regulated alternative splicing? Biochimica et biophysica acta 1630:1-6.

Schneider JW. 2013. Caveats for using statistical significance tests in research assessments. Journal of Informetrics 7:50-62.

Stevens LA., Levey AS. 2009. Current status and future perspectives for CKD testing. American journal of kidney diseases : the official journal of the National Kidney Foundation 53:S1726.

Vuong MT., Lundberg S., Gunnarsson I., Wramner L., Seddighzadeh M., Hahn-Zoric M., Fernstrom A., Hanson LA., Do LT., Jacobson SH., Padyukov L. 2009. Genetic variation in the transforming growth factor- 1 gene is associated with susceptibility to IgA nephropathy. Nephrology Dialysis Transplantation 24:3061-3067.

Wendt TM., Tanji N., Guo J., Kislinger TR., Qu W., Lu Y., Bucciarelli LG., Rong LL., Moser B., Markowitz GS., Stein G., Bierhaus A., Liliensiek B., Arnold B., Nawroth PP., Stern DM., D’Agati VD., Schmidt AM. 2003. RAGE drives the development of glomerulosclerosis and implicates podocyte activation in the pathogenesis of diabetic nephropathy. The American journal of pathology 162:1123-37.

Xie J., Méndez JD., Méndez-Valenzuela V., Aguilar-Hernández MM. 2013. Cellular signalling of the receptor for advanced glycation end products (RAGE). Cellular signalling 25:218597.

Yonekura H., Yamamoto Y., Sakurai S., Petrova RG., Abedin MJ., Li H., Yasui K., Takeuchi M., Makita Z., Takasawa S., Okamoto H., Watanabe T., Yamamoto H. 2003. Novel splice variants of the receptor for advanced glycation end-products expressed in human vascular endothelial cells and pericytes, and their putative roles in diabetes-induced vascular injury. The Biochemical journal 370:1097-109.

Zee RYL., Romero JR., Gould JL., Ricupero D a., Ridker PM. 2006. Polymorphisms in the advanced glycosylation end product-specific receptor gene and risk of incident myocardial infarction or ischemic stroke. Stroke; a journal of cerebral circulation 37:1686-90. 
Table 1. RAGE G82S, -374T/A, -429T/C and 1704G/T polymorphism identification, assay identification and location

\begin{tabular}{lccc}
\hline Polymorphism & Polymorphism ID & Assay ID * & Location \\
\hline G82S & rs2070600 & C__15867521_20 & Chr.6: 32151443 \\
-374T/A & rs1800624 & C__3293837_1_ & Chr.6: 32152387 \\
$-429 T / C$ & rs 1800625 & C__8848033_1_ & Chr.6: 32152442 \\
1704G/T & rs184003 & C__ 2412456_10 & Chr.6: 32150296 \\
2184A/G & rs3134940 & Custom assay & Chr.6: 32149816
\end{tabular}

466

$467 *$ Assay ID of TaqMan ${ }^{\circledR}$ SNP Genotyping Assay (Life Technologies, USA)

468

469

470

471

472

473

474

475

476

477 
Table 2. Demographic data, estimated glomerular filtration rate and comorbidities of non-diabetic chronic kidney disease (CKD) patients, diabetic chronic kidney disease patients and healthy controls

\begin{tabular}{|c|c|c|c|c|c|c|}
\hline & Non-diabetic CKD & & & $\boldsymbol{P}_{a}$ & $\boldsymbol{P}_{b}$ & $\boldsymbol{P}_{c}$ \\
\hline & patients & Diabetic CKD patients & Healthy controls & & & \\
\hline & $\mathrm{n}=102$ & $\mathrm{n}=204$ & $\mathrm{n}=345$ & & & \\
\hline Age (years) & $62.98 \pm 8.70$ & $64.61 \pm 7.44$ & $43.86 \pm 6.30$ & 0.141 & $<0.001$ & $<0.001$ \\
\hline Gender (male/female) & $66 / 36$ & $129 / 75$ & $204 / 141$ & 0.801 & 0.311 & 0.341 \\
\hline $\begin{array}{l}\text { Ethnic groups } \\
\text { (Malay/Indian/Chinese) }\end{array}$ & $33 / 51 / 18$ & $84 / 74 / 46$ & $127 / 146 / 72$ & 0.071 & 0.387 & 0.373 \\
\hline eGFR at recruitment $\left(\mathrm{ml} / \mathrm{min} / 1.73 \mathrm{~m}^{2}\right)$ & $32.51 \pm 14.51$ & $27.04 \pm 11.81$ & Not available & 0.001 & - & - \\
\hline Hypertension (\%) & 73.5 & 83.3 & Not available & 0.043 & - & - \\
\hline Dyslipidemia (\%) & 30.4 & 26.0 & Not available & 0.415 & - & - \\
\hline Ischemic heart disease $(\%)$ & 11.8 & 27.0 & Not available & 0.002 & - & - \\
\hline Stroke (\%) & 3.9 & 5.9 & Not available & 0.468 & - & - \\
\hline
\end{tabular}

Data are expressed as mean \pm standard deviation, except for categorical variables, which are reported as numbers or percentages. $P_{a}$, $\mathrm{P}$-value for non-diabetic $\mathrm{CKD}$ patients versus diabetic CKD patients; $P_{b}, \mathrm{P}$-value for non-diabetic CKD patients versus healthy controls; $P_{c}$, P-value for diabetic CKD patients versus healthy controls. 
Table 3. Association of RAGE G82S, -374T/A, -429T/C, 1704G/T, 2184A/G and 63-bp deletion polymorphisms with chronic kidney disease in Malaysian population

\begin{tabular}{|c|c|c|c|c|c|c|c|c|}
\hline \multirow{2}{*}{$\begin{array}{c}\text { Polymorphis } \\
\text { m }\end{array}$} & \multirow{2}{*}{$\begin{array}{c}\text { Allele } \\
1 / 2 \\
\end{array}$} & \multirow[t]{2}{*}{ Subjects } & \multirow{2}{*}{$\begin{array}{c}\text { Genotype } 12+22 \\
\text { n }(\%) \\
\end{array}$} & \multirow[t]{2}{*}{ Comparison } & \multicolumn{2}{|r|}{ Model 1} & \multicolumn{2}{|r|}{ Model 2} \\
\hline & & & & & $\boldsymbol{P}$ & OR $(95 \%$ CI $)$ & $\boldsymbol{P}$ & OR $(95 \%$ CI $)$ \\
\hline \multirow[t]{3}{*}{ G82S } & $\mathrm{C} / \mathrm{T}$ & ND-CKD & $39(38.2)$ & ND-CKD vs D-CKD & 0.015 & $1.896(1.132$ to 3.176$)$ & 0.011 & $2.024(1.178$ to 3.476$)$ \\
\hline & & D-CKD & $51(25.0)$ & ND-CKD vs HC & 0.749 & $1.135(0.522$ to 2.467$)$ & 0.598 & $1.440(0.372$ to 5.576$)$ \\
\hline & & $\mathrm{HC}$ & $90(26.1)$ & D-CKD vs HC & 0.128 & $0.533(0.237$ to 1.199$)$ & 0.815 & $1.207(0.249$ to 5.863$)$ \\
\hline \multirow[t]{3}{*}{$-374 \mathrm{~T} / \mathrm{A}$} & $\mathrm{T} / \mathrm{A}$ & ND-CKD & $22(21.6)$ & ND-CKD vs D-CKD & 0.644 & $0.873(0.490$ to 1.554$)$ & 0.430 & $0.787(0.435$ to 1.425$)$ \\
\hline & & D-CKD & $48(23.5)$ & ND-CKD vs HC & 0.408 & $1.480(0.585$ to 3.743$)$ & 0.642 & $1.451(0.302$ to 6.967$)$ \\
\hline & & $\mathrm{HC}$ & $83(24.1)$ & D-CKD vs HC & 0.294 & $1.556(0.682$ to 3.551$)$ & 0.113 & $4.261(0.710$ to 25.567$)$ \\
\hline \multirow[t]{3}{*}{$-429 \mathrm{~T} / \mathrm{C}$} & $\mathrm{T} / \mathrm{C}$ & ND-CKD & $16(15.7)$ & ND-CKD vs D-CKD & 0.134 & $0.617(0.328$ to 1.160$)$ & 0.110 & $0.588(0.306$ to 1.128$)$ \\
\hline & & D-CKD & $46(22.6)$ & ND-CKD vs HC & 0.735 & $0.848(0.326$ to 2.205$)$ & 0.616 & $1.533(0.288$ to 8.159$)$ \\
\hline & & $\mathrm{HC}$ & $81(23.5)$ & D-CKD vs HC & 0.103 & $1.948(0.874$ to 4.342$)$ & 0.054 & $5.727(0.972$ to 33.731$)$ \\
\hline \multirow[t]{3}{*}{$1704 \mathrm{G} / \mathrm{T}$} & $\mathrm{G} / \mathrm{T}$ & ND-CKD & $42(41.2)$ & ND-CKD vs D-CKD & 0.284 & $1.309(0.799$ to 2.143$)$ & 0.208 & $1.385(0.835$ to 2.299$)$ \\
\hline & & D-CKD & $70(34.3)$ & ND-CKD vs HC & 0.619 & $1.217(0.562$ to 2.636$)$ & 0.490 & $0.604(0.144$ to 2.527$)$ \\
\hline & & $\mathrm{HC}$ & $125(36.2)$ & D-CKD vs HC & 0.799 & $1.100(0.529$ to 2.287$)$ & 0.834 & $0.853(0.193$ to 3.763$)$ \\
\hline \multirow[t]{3}{*}{$2184 \mathrm{~A} / \mathrm{G}$} & $\mathrm{A} / \mathrm{G}$ & ND-CKD & $16(15.7)$ & ND-CKD vs D-CKD & 0.134 & $0.617(0.328$ to 1.160$)$ & 0.110 & $0.588(0.306$ to 1.128$)$ \\
\hline & & D-CKD & $46(22.6)$ & ND-CKD vs HC & 0.725 & $0.842(0.324$ to 2.189$)$ & 0.618 & $1.530(0.287$ to 8.144$)$ \\
\hline & & $\mathrm{HC}$ & $82(23.8)$ & D-CKD vs HC & 0.105 & $1.941(0.871$ to 4.324$)$ & 0.054 & $5.725(0.971$ to 33.741$)$ \\
\hline \multirow{3}{*}{$\begin{array}{c}\text { 63-bp } \\
\text { deletion }\end{array}$} & _/del & ND-CKD & $4(3.9)$ & ND-CKD vs D-CKD & 0.735 & $1.244(0.352$ to 4.392$)$ & 0.863 & $1.120(0.308$ to 4.069$)$ \\
\hline & & D-CKD & $7(3.4)$ & ND-CKD vs HC & 0.273 & $0.303(0.036$ to 2.560$)$ & 0.387 & $0.268(0.014$ to 5.283$)$ \\
\hline & & $\mathrm{HC}$ & $24(7.0)$ & D-CKD vs HC & 0.100 & $0.232(0.041$ to 1.320$)$ & 0.423 & $0.312(0.018$ to 5.393$)$ \\
\hline
\end{tabular}




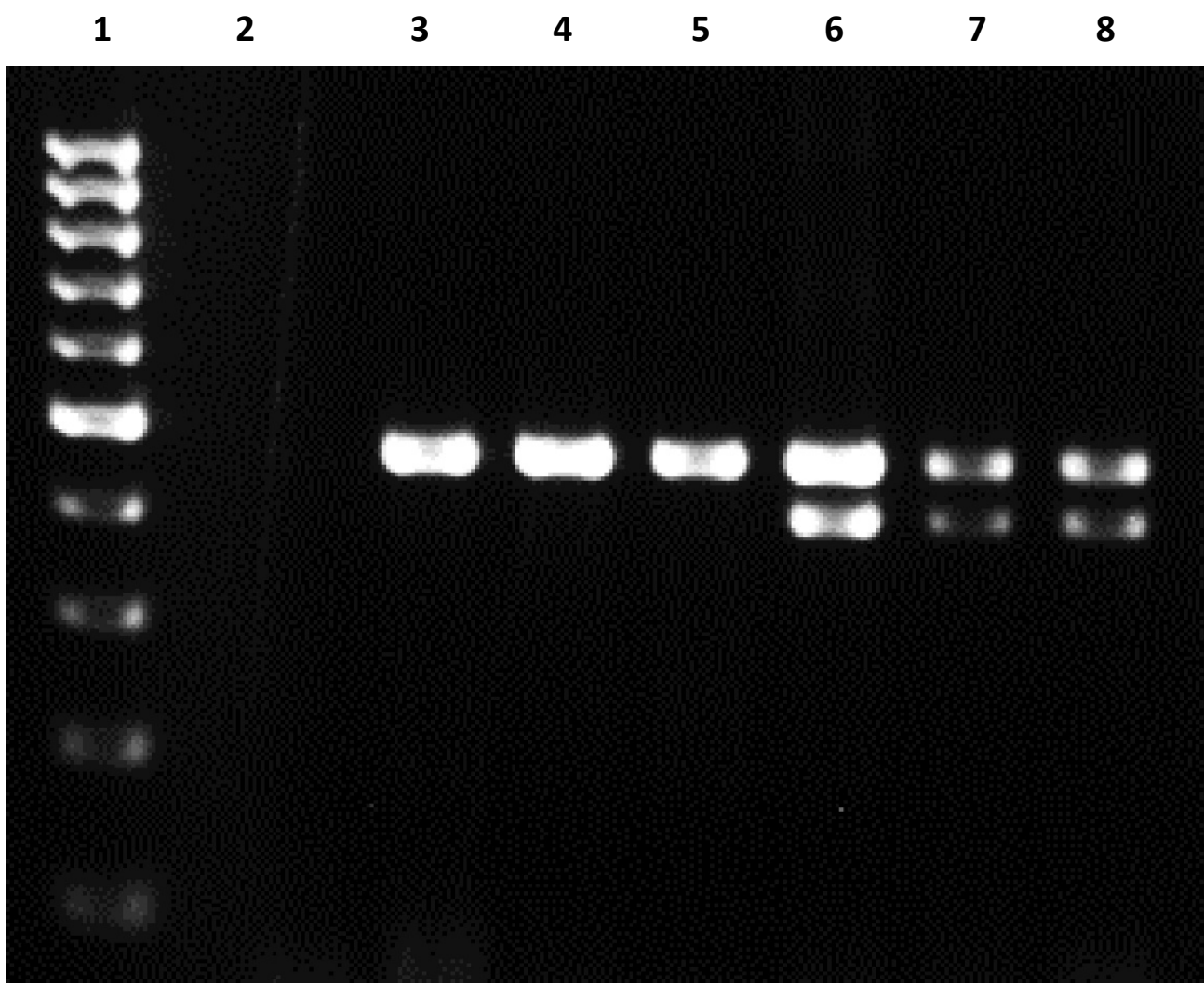

Figure 1. Representative gel image of electrophoresed PCR products with or without 63-bp deletion. Lane 1: 100 bp DNA ladder; lane 2: non-template blank; lanes 3 - 5: selected DNA samples without 63-bp deletion (containing a 474-bp band); lanes 6 - 8: selected DNA samples which are heterozygous for 63-bp deletion (containing a 474-bp band corresponding to sequence without 63-bp deletion and a 411-bp band corresponding to sequence with 63-bp deletion). 

20

\section{Supplementary information}

Table S1. Chi-squared values of Hardy-Weinberg equilibrium tests on non-diabetic CKD patients, diabetic CKD patients and healthy controls

\begin{tabular}{|c|c|c|c|c|c|c|}
\hline \multirow[t]{2}{*}{ Subjects } & \multicolumn{6}{|c|}{ RAGE polymorphisms } \\
\hline & G82S & $-374 \mathrm{~T} / \mathrm{A}$ & $-429 \mathrm{~T} / \mathrm{C}$ & 1704G/T & $2184 A / G$ & $\begin{array}{c}\text { 63-bp } \\
\text { deletion }\end{array}$ \\
\hline $\begin{array}{l}\text { Non-diabetic CKD } \\
\text { patients }\end{array}$ & 0.10 & 0.31 & $5.85^{*}$ & 0.45 & 0.74 & 0.04 \\
\hline Diabetic CKD patients & $6.56^{*}$ & 0.01 & 0.00 & $6.81^{*}$ & 3.29 & 0.06 \\
\hline Healthy controls & 0.01 & 2.97 & 0.06 & 3.21 & $6.28^{*}$ & 0.45 \\
\hline
\end{tabular}

\footnotetext{
* Hardy-Weinberg equilibrium was violated at $P<0.05$, corresponding to a Chi-squared values of 3.84 at 1 degree of freedom.
}

\section{4} 然 16 (1) 


\section{2 \\ Supplementary information}

Table S2. Statistical power of case-control comparison of genotype frequencies

\begin{tabular}{|c|c|c|c|c|c|c|}
\hline \multirow[t]{2}{*}{ Comparison } & \multicolumn{6}{|c|}{ RAGE polymorphisms } \\
\hline & G82S & $-374 \mathrm{~T} / \mathrm{A}$ & $-429 \mathrm{~T} / \mathrm{C}$ & 1704G/T & $2184 A / G$ & $\begin{array}{c}\text { 63-bp } \\
\text { deletion }\end{array}$ \\
\hline $\begin{array}{l}\text { ND-CKD vs D- } \\
\text { CKD }\end{array}$ & 78.1 & 12.8 & 39.6 & 26.1 & 38.0 & 5.4 \\
\hline ND-CKD vs HC & 31.5 & 26.3 & 39.4 & 54.9 & 38.1 & 57.9 \\
\hline D-CKD vs HC & 15.9 & 99.9 & 99.9 & 13.9 & 99.9 & 73.4 \\
\hline
\end{tabular}

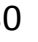
1 34

Statistical power is expressed in percentages (\%). Abbreviations in the table - ND-CKD, non-diabetic CKD; D-CKD, diabetic CKD; $\mathrm{HC}$, healthy control. (n) 


\section{Supplementary information}

538

(a) Sequence without 63-bp deletion

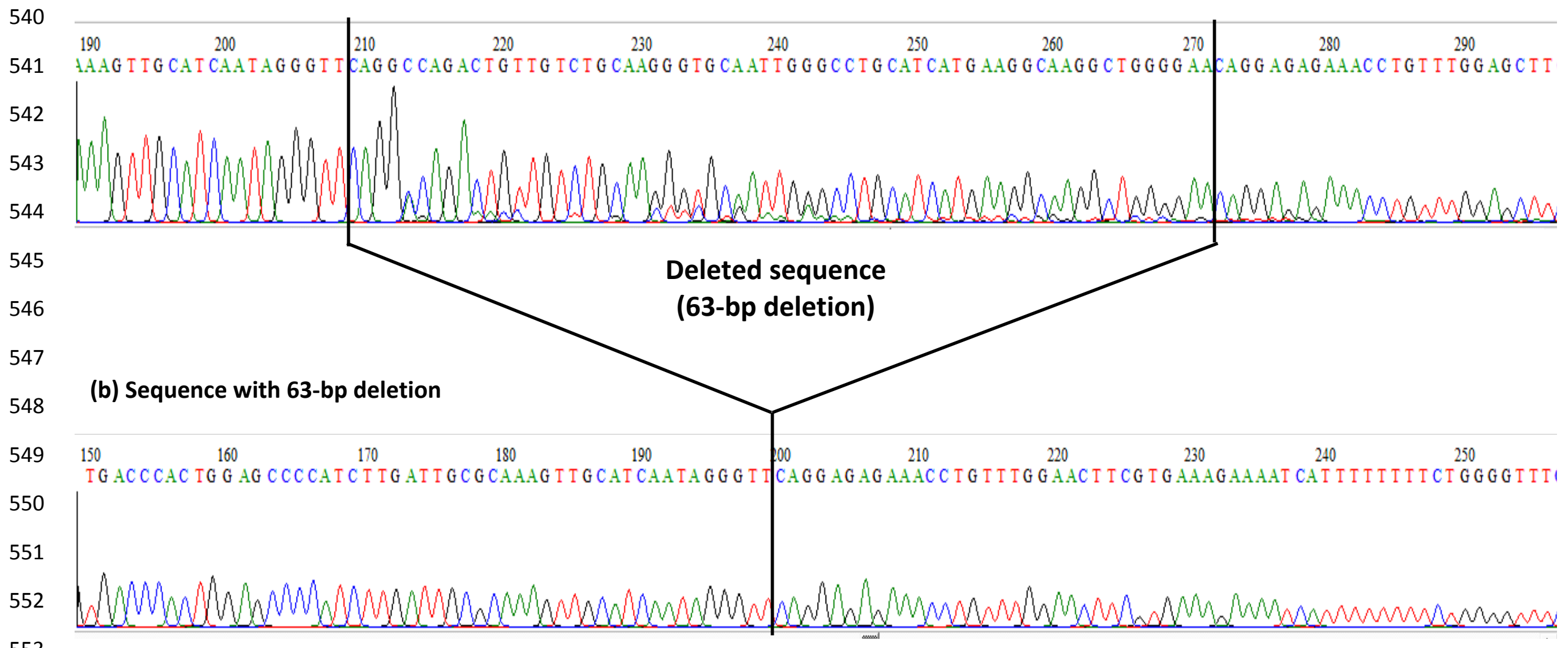

Figure S1. DNA sequences with and without 63-bp deletion. (a) The DNA sequence without 63-bp deletion contains a stretch of 